\title{
Risk of primary biliary liver cirrhosis in patients with coeliac disease: Danish and Swedish cohort data
}

\author{
H T Sørensen, A M Thulstrup, P Blomqvist, B Nørgaard, K Fonager, A Ekbom
}

Danish Epidemiology Science Centre, Department of Epidemiology and Social Medicine, Aarhus University, DK-8000 Aarhus C, Denmark

H T Sørensen

A $M$ Thulstrup

B Nørgaard

Department of Internal Medicine V, Aarhus University Hospital, DK-8000 Aarhus C, Denmark H T Sørensen A $M$ Thulstrup B Norgård

Department of Medical Epidemiology, Karolinska Institutet, PO Box 281, SE-171 77 Stockholm, Sweden P Blomqvist

A Ekbom

Department of Internal Medicine M, Aalborg Hospital, DK-9000 Aalborg, Denmark

K Fonager

Department of Epidemiology and the Harvard Centre for Cancer Prevention, Harvard School of Public Health, Boston, MA 02115, USA A Ekbom

Correspondence to: Dr H T Sørensen, The Danish Epidemiology Science Centre at the Department of Epidemiology and Social Medicine, Aarhus University, DK-8000 Aarhus C, Denmark.

Accepted for publication 17 December 1998

\begin{abstract}
Background-Several case reports, but only a few studies, have examined the coexistence of coeliac disease and primary biliary cirrhosis.

Aim-To estimate the risk of primary biliary cirrhosis in two national cohorts of patients with coeliac disease in Denmark and Sweden.

Methods-Through record linkage all Danish patients hospitalised with coeliac disease were followed for possible occurrence of primary biliary cirrhosis from 1 January 1977 until 31 December 1992. All patients hospitalised with coeliac disease in Sweden from 1987 to 1996 were also followed in a separate analysis.

Results-A total of 896 patients with coeliac disease were identified in Denmark with a median follow up period of 9.1 years for a total of 8040 person-years at risk. Two cases of primary biliary cirrhosis were observed where 0.07 were expected, giving a standardised incidence ratio of 27.6 (95\% confidence interval 2.9 to 133.5 ). A total of 7735 patients with coeliac disease were identified in Sweden with a median follow up period of 5.1 years for a total of 39284 person-years at risk. Twenty two people with primary biliary cirrhosis were identified compared with 0.88 expected, giving a standardised incidence ratio of 25.1 (95\% confidence interval 15.7 to 37.9 ).
\end{abstract}

Conclusion-Patients with coeliac disease are at increased risk of having primary biliary cirrhosis.

(Gut 1999;44:736-738)

Keywords: coeliac disease; primary biliary cirrhosis; epidemiology; risk

Our knowledge of coeliac disease has increased during the past few decades, and a number of other diseases seem to be associated with it. ${ }^{1-10}$ Documentation of such associations is often based on case reports or small series, ${ }^{8}$ very few of which have been studied with proper epidemiological designs. Twenty years ago, Logan et $a l^{9}$ reported the coexistence of coeliac disease and primary biliary cirrhosis in four patients. A recent British study showed a prevalence of primary biliary cirrhosis of 3\% in 143 patients with coeliac disease. ${ }^{11}$ The authors concluded that coeliac disease and primary biliary cirrhosis were associated, and that patients with one of these diseases should be screened for the other. ${ }^{12}$ The associations were tested by prevalence measures, but the strength of an association between two diseases may be biased, as the prevalence is a function of both incidence and disease duration. Thus, it is necessary to quantify the risk before the question of screening can be considered. Computerised nationwide registration systems in Denmark and Sweden allowed us to undertake two population based evaluations of the strength of an association between coeliac disease and primary biliary cirrhosis.

\section{Methods}

The Danish National Registry of Patients was established in 1977 and covers $99.4 \%$ of all discharges from hospitals in Denmark (population 5.2 million). ${ }^{13}$ Recorded information includes the personal civil registration number, assigned to every Danish citizen at birth, dates of admission and discharge, and up to 20 discharge diagnoses, classified according to the Danish version of the International Classification of Diseases, 8th edition (ICD-8). ${ }^{14}$ Discharge records were linked through the civil registration number. All patients in the National Registry of Patients from 1 January 1977 to 31 December 1992 were enrolled in the study when they had received the discharge diagnosis coeliac disease (ICD 269.0) during at least one of their hospital stays.

Cases of primary biliary cirrhosis were also identified in the National Registry of Patients. All members of the study cohort were linked by their civil registration number to the nationwide Central Personal Registry, which contains information on deaths, migration, and immigration. Patients were followed until 31 December 1992 or their death, whichever came first.

The Swedish National Inpatient Registry covers all admissions to public health care in Sweden from 1987 onwards. ${ }^{15}$ We identified all admissions from 1987 to 1996 with a primary or secondary diagnosis of coeliac disease (ICD9 579A) and primary biliary cirrhosis (ICD9 571G). In addition to demographic and administrative data, the Swedish Inpatient Registry, in a manner similar to the Danish system, also records the personal civil registration number for each Swedish citizen.

We calculated the standardised incidence ratio for the two cohorts mentioned by comparing the observed incidence rate with the expected. We also calculated $95 \%$ confidence intervals (CI) according to exact Poisson limits, but if the observed number was less than 10 we used the exact limits. 


\section{Results}

We identified a total of 896 patients in Denmark with coeliac disease, corresponding to an annual incidence rate of 1.1 per 100000 . A total of 793 patients with primary biliary cirrhosis were identified, corresponding to an annual incidence rate of 0.9 per 100000 . We followed the Danish patients with coeliac disease for a median period of 9.1 years (quartile 4.5-13.3), or a total of 8040 person-years. Among these, two patients had primary biliary cirrhosis, one woman and one man. The expected number was 0.07 , giving a standardised incidence ratio of 27.6 (95\% CI 2.9 to 133.5).

We identified a total of 7735 patients in Sweden with coeliac disease, corresponding to an annual incidence rate of 9.0 per 100000 . A total of 1921 patients with primary biliary cirrhosis were identified, corresponding to an annual incidence rate of 2.2 per 100000 .

We followed the 7735 Swedish patients with coeliac disease for a median of 5.1 years (quartile 2.5-7.7), or a total of 39284 person-years. Among these, 22 patients had primary biliary cirrhosis, 15 women and seven men. The expected number of primary biliary cirrhosis cases during the study period was 0.88 , giving a standard incidence ratio of 25.1 (95\% CI 15.7 to 37.9 ).

\section{Discussion}

Our results strongly support the hypothesis that primary biliary cirrhosis is associated with coeliac disease. A strength of our study is that this association was presented in two independent national data sources during two different periods. The uniformly organised public health care systems in Denmark and Sweden enabled a population based design. Thus a common bias in hospital based studies introduced by differential patient recruitment was avoided, and completeness of follow up was ensured. Selection bias can therefore be reduced with a design relying on computerised linkage within databases with virtually complete nationwide coverage of the population.

The cohorts presented are among the most comprehensive reported, with regard to observation time, sample size, and follow up time. Our study also considered the time period at risk. As we used data from inpatient care, we have no information on patients treated only as outpatients. Consequently the detected associations provide a conservative estimate.

Information bias cannot be excluded because patients with coeliac disease are under more intensive surveillance for possible development of liver diseases. Our study was based on discharge diagnoses, and it is well known that these may vary in quality. However, Danish data quality studies have shown a completeness and validity of more than $90 \%$ for gastrointestinal and liver diseases. ${ }^{16}{ }^{17}$ There may also be a risk of Berkson's fallacy, or if one disease influences the probability of hospitalisation, other diseases are also more easily diagnosed, and hospital discharge data may thus wrongly indicate an association between the two diseases. ${ }^{18}$ However, the strength of the detected association does not support this.

Several studies have shown that patients with coeliac disease have symptoms several years before their first hospital stay. ${ }^{19}{ }^{20}$ Therefore the calculated follow up time period may be underestimated, but the reported incidence of primary biliary cirrhosis and coeliac disease in earlier Danish studies corresponds well to our findings in Denmark. ${ }^{21} 22$ The reported prevalence and incidence rates in earlier local Swedish studies also correspond well to the findings in Sweden. ${ }^{23-25}$

It has been suggested that the association between coeliac disease and primary biliary cirrhosis represents a shared susceptibility of biliary and small bowel epithelium to attack by autoimmune mechanisms. ${ }^{11}$ As primary biliary cirrhosis can be diagnosed by non-invasive tests with high sensitivity and specificity, and can be treated with urodeoxycholic acid or by liver transplantation, screening has been recommended. ${ }^{12}$

Before the question of screening patients with coeliac disease for primary biliary cirrhosis can be settled, it is worth discussing some of the facts presented so far. Before our study, the association between coeliac disease and primary biliary cirrhosis had been quantified only by prevalence data. After all, both diseases are rare, with low incidence rates. Among our patients, only three per 1000 with coeliac disease also suffered from primary biliary cirrhosis, a very rare combination in a rare disease.

Screening to detect incident cases with this exceedingly uncommon combination is a major undertaking in any health care system. Considering the underlying incidence rate, the performance of any testing system in routine health care, and the costs, including those of further testing of false positive cases, the cost effectiveness is questionable. Furthermore, patients with coeliac disease are already monitored regularly in most developed countries.

In conclusion, we found a high risk of primary biliary cirrhosis in patients with coeliac disease. The risk was similar when assessed independently in two different national hospital data bases during two different study periods.

The activities of the Danish Epidemiology Science Centre are financed by a grant from the Danish National Research Foundation. The study was funded by the Danish Research Academy.

1 Visakorpi JK. Diabetes and coeliac disease. Lancet 1969 ;ii: 1192

2 Thain ME, Hamilton JR, Ehrlich RM. Coexistence of diabetes mellitus and coeliac disease. $\mathcal{F}$ Pediatr 1974;85: 5279

3 Scott BB, Losowsky MS. Coeliac disease: a cause of various associated diseases. Lancet 1975;ii:956.

4 Cooper BT, Holmes GTK, Cooke WT. Coeliac disease and immunological disorders. BMF 1978;i:537-9.

5 Collin P, Salmi J, Hällström O, et al. High frequency of coeliac disease in adult patients with type I diabetes. Scand $\mathcal{F}$ Gastroenterol 1989;24:81-4.

6 Collin P, Salmi J, Hällström O, et al. Autoimmune thyroid disorders and coeliac disease. Eur $\mathcal{F}$ Endocrinol 1994;130: 137-40.

7 Jacobsen MB, Fausa O, Elgjo K, et al. Hepatic lesions in adult coeliac disease. Scand $\mathcal{F}$ Gastroenterol 1990;25:65662 .

8 Collin P, Mäki M. Associated disorders in coeliac disease: clinical aspects. Scand $\mathcal{F}$ Gastroenterol 1994; 29:769-75. 
9 Logan RFA, Ferguson A, Finlayson NDC, et al. Primary biliary cirrhosis and coeliac disease, an association. Lancet biliary cirrhosis

$10 \mathrm{Behr}$ W, Barnert J. Adult celiac disease and primary biliary cirrhosis. Am $\mathcal{f}$ Gastroenterol 1986;81:769-9.

11 Kingham JGC, Parker DR. The association between biliary cirrhosis and coeliac disease: a study of relative prevalences. Gut 1998;42:120-2.

12 Metcalf J. Coeliac disease and primary biliary cirrhosis: a case for mutual screening. Gut 1998;42:9-10.

13 Danish National Board of Health. The activity in the hospital care system. Copenhagen: National Board of Health, 1981.

14 Danish National Board of Health. Classification of diseases. Copenhagen: National Board of Health, 1976.

15 Blomqvist $\mathrm{P}$, Ljung $\mathrm{H}$, Nyren $\mathrm{O}$, et al. Appendectomy in Sweden 1989-1993 assessed by the Inpatient Registry. F Clin Epidemiol 1998;51:859-65.

16 Fonager K, Sørensen HT, Rasmussen SN, et al. Assessment of the diagnoses of Crohn's disease and ulcerative colitis in a Danish hospital information system. Scand $\mathcal{f}$ Gastroenterol 1996;31:154-9.

17 Vestberg K, Thulstrup AM, Sørensen HT, et al. Data quality of admini for liver cirrhosis epidemiology. $\mathcal{F}$ Med Syst 1997;21:11-20.
18 Berkson J. Limitations of the application of fourfold table analysis to hospital data. Biomedical Bulletin 1946;2:47-53.

19 Bode S, Gudmand-Høyer E. Symptoms and haematologic features in consecutive adult coeliac patients. Scand F Gastroenterol 1996;31:54-60.

20 Dickey W, McConnell JB. How many hospital visits does it ake before celiac sprue is diagnosed? $\mathcal{F}$ Clin Gastroenterol 1996;23:21-3.

21 Almdal TP, Sørensen TIA. Incidence of parenchymal liver diseases in Denmark, 1981 to 1985 . Analysis of hospitalization registry data. Hepatology 1991;13:650-5.

22 Bode S, Gudmand-Høyer E. Incidence and prevalence of adult coeliac disease within a defined geographic area in Denmark. Scand f Gastroenterol 1996;31:694-9

23 Midhagen G, Jarnerot G, Kraaz W. Adult coeliac disease within a defined geographic area in Sweden. A study of prevalence and associated diseases. Scand 7 Gastroenterol 1988;23:1000-4.

24 Danielsson A, Boqvist L, Uddenfeldt P. Epidemiology of primary biliary cirrhosis in a defined rural population in the primary biliary cirrhosis in a defined rural population in the

25 Eriksson S, Lindgren S. The prevalence and clinical spectrum of primary biliary cirrhosis in a defined population. Scand $\mathcal{F}$ Gastroenterol 1984;19;971-6. 